\title{
Stretchable Biofuel Cell with Enzyme-Modified Conductive Textiles
}

\author{
Yudai Ogawa, Yuki Takai, Yuto Kato, Hiroyuki Kai, Takeo Miyake, Matsuhiko Nishizawa* \\ Department of Bioengineering and Robotics, Tohoku University, 6-6-1 Aramaki Aoba, Aoba-ku, Sendai \\ 980-8579, Japan \\ ${ }^{*}$ Corresponding authors. Tel./Fax: +81-22-795-7003. \\ E-mail address: nishizawa@biomems.mech.tohoku.ac.jp. (M. Nishizawa) \\ Key words: stretchable, biofuel cell, carbon nanotube
}

\begin{abstract}
A sheet-type, stretchable biofuel cell was developed by laminating three components: a bioanode textile for fructose oxidation, a hydrogel sheet containing fructose as fuel, and a gas-diffusion biocathode textile for oxygen reduction. The anode and cathode textiles were prepared by modifying carbon nanotube (CNT)-decorated stretchable textiles with fructose dehydrogenase (FDH) and bilirubin oxidase (BOD), respectively. Enzymatic reaction currents of anode and cathode textiles were stable for 30 cycles of $50 \%$ stretching, with initial loss of $20-30 \%$ in the first few cycles due to the partial breaking of the CNT network at the junction of textile fibers. The assembled laminate biofuel cell showed power of $\sim 0.2 \mathrm{~mW} / \mathrm{cm}^{2}$ with $1.2 \mathrm{k} \Omega$ load, which was stable even at stretched, twisted, and wrapped forms.
\end{abstract}

\section{Introduction}

Stretchable devices have recently attracted much attention in large-area electronics (Someya, 2012). In particular, there have been many attempts to make functional artificial skin (Hammock et al., 2013), display panels (Park et al., 2009; Sekitani et al., 2009), health-care devices (Yamada et al., 2011; Hattori et al., 2014), etc. Normally, such emerging circuits are formed with soft materials to withstand a twisted, folded and wrapped form, and contain some electrical components, e.g. conductive wires, electrical devices, and sensors. As an indispensable component of stretchable electronics, a power source element should be able to accommodate large strain while retaining its performance. To date, some efforts have been made in developing stretchable energy conversion devices such as solar cells (Lipomi et al., 2011), supercapacitors (Hu et al., 
2010), and piezoelectric generators (Qi et al., 2011). As well as such power sources, enzymatic biofuel cells (BFCs) that generate electricity through enzymatic oxidation of biological fuels such as sugars and alcohols have been expected as ubiquitous, safe power sources (Barton et al., 2004; Heller, 2004; Cooney et al., 2008; Meredith and Minteer, 2012; Kwon et al., 2014; Luckarift et al., 2014). BFCs can be built entirely with organic materials, and therefore can be disposable and biocompatible. It is also possible to energy harvesting from body fluid like blood and sweat (Jia et al., 2013a, 2013b, 2014; Bandodkar and Wang 2014; Cosnier et al., 2014). Recently, the wearable BFC has been reported by mounting BFCs on an adhesive tape or a headband (Jia et al., 2013b, 2014). However, there is no report on a stretchable BFC, in which the enzyme electrodes themselves have stretchability, as far as we know.

Here, we describe a stretchable BFC constructed by laminating enzyme-modified conductive textiles and a hydrogel film containing an electrolyte and fuel as shown in Figure 1. We took advantage of the design of sheet-shaped BFCs which we developed previously using non-stretchable carbon fiber fabric as the electrode substrates (Miyake et al., 2013). To make stretchable a BFC sheet, we employ a nylon/polyurethane co-fiber textile as an underlying base material. This stretchable but insulating textile was modified with the CNTs to be conductive enough for enzyme electrodes. The stretchability of the laminate cell was demonstrated in stretched, twisted, and wrapped forms to power a light-emitting diode (LED) device.

[Fig.1]

\section{Materials and Methods}

\section{Preparation of CNT-Modified Pantyhose Textile}

A $5 \mathrm{~mm} \times 10 \mathrm{~mm}$ strip (0.18 mm thickness) of a commercial stretchable pantyhose textile (ST; SP-723, purchased from GUNZE) was first modified with CNTs to make an electrical network on the surface of the ST and increase specific surface area. The stretchability of the ST originates from its change in the submillimeter-scale meshwork matrix constructed from nylon/polyurethane co-fibers (Supplementary Figure S1a). In this work, two types of CNT were used. One is a super-growth single-walled carbon nanotube (SCNT; donated from Dr. Kenji Hata), which is extremely long (200 $\mu \mathrm{m}$ in average) and shows higher conductivity than conventional CNTs (Ata et al., 2012). SCNTs were modified on the virgin ST to achieve high conductivity for an enzyme electrode. Another CNT used is a comparatively short (5 $\mu \mathrm{m}$ in average) multi-walled 
carbon nanotube (MCNT; purchased from Bayer Materials Science Co.)

A $100 \mu \mathrm{l}$ aliquot of $5 \mathrm{mg} / \mathrm{ml}$ SCNT dispersion containing 1\% sodium deoxycholate was dropped onto an ST strip $(1 \mathrm{~cm} \times 1 \mathrm{~cm})$ and dried in air. MCNTs were pretreated by heating at $400{ }^{\circ} \mathrm{C}$ for $11 \mathrm{~h}$ and by immersing in mixed acid $\left(\mathrm{H}_{2} \mathrm{SO}_{4} / \mathrm{HNO}_{3}, 1: 3 \mathrm{v} / \mathrm{v}\right.$ ratio) for $5 \mathrm{~h}$. A $50 \mu \mathrm{l}$ aliquot of the $10 \mathrm{mg} / \mathrm{ml}$ MCNT dispersion containing 1\% Triton X-100 was dropped on a virgin ST strip or the SCNT-modified ST strip, followed by air drying. After degassing the CNT-modified strip by immersion in stirred distilled water for more than 1 h under vacuum, the CNT-modified strip became hydrophilic.

\section{Preparation of Fructose Anode}

The MCNT/SCNT/ST strip was first immersed in a stirred solution of D-fructose dehydrogenase (FDH) (EC1.1.99.11, $169.9 \mathrm{U} \mathrm{mg}^{-1}$, ca. $140 \mathrm{kDa}$, from Gluconobacter, purchased from Toyobo Enzyme Co.) for $1.5 \mathrm{~h}$ to immobilize FDH (Tominaga et al., 2009; Tsujimura et al., 2010; Miyake et al., 2011a, 2013). It has been reported that FDH works as an electrocatalyst for two-electron oxidation of fructose (Tominaga et al., 2007; Murata et al., 2009). Surface area of $0.5 \mathrm{~cm}^{2}$ was used for calculation of the current density in cyclic voltammetry (CV).

\section{Preparation of $\mathrm{O}_{2}$-Diffusion Cathode}

Preparation of the cathode basically followed the procedures used for our previous bilirubin oxidase (BOD, EC 1.3.3.5, $2.5 \mathrm{U} \mathrm{mg}^{-1}$, from Myrothecium)-modified carbon fabric cathode (Miyake et al., 2011a; Miyake et al., 2013). BOD is a multi-copper oxidase that can directly catalyze four-electron reduction of $\mathrm{O}_{2}$ to $\mathrm{H}_{2} \mathrm{O}$ even in the absence of electron transfer mediators (Shleev et al., 2005; Mano and Edembe 2013; So et al., 2014). The surface of the CNT-modified ST strip was further modified with a 1 $\mathrm{ml}$ solution of $10 \mathrm{mg} \mathrm{ml}^{-1}$ BOD in a vacuum oven (AVO-205N, purchased from AS ONE, $35 \mathrm{C}$ ). The strip was additionally coated with the MCNT dispersed in ethanol with $1.0 \mathrm{wt} \%$ polytetrafluoroethylene (PTFE) as a binder. Surface area of $0.5 \mathrm{~cm}^{2}$ was used for calculation of the current density in $\mathrm{CV}$.

\section{Preparation of Hydrogel Films}

Fructose-containing double-network (DN) hydrogel films were prepared by a three-step process (Gong et al., 2003; Gong, 2010; Wu and Gong, 2011): (1) single network hydrogel formation, (2) second network formation into the single network hydrogel, and (3) loading of $200 \mathrm{mM}$ fructose (Supplementary Figure S2). We used stock solutions A and B. Solution A contains 2-acrylamido-2-methlypropane (AMPS, 1 
M), N,N-methylenebisacrylamide (MBAA, $40 \mathrm{mM}$ ), 2-oxoglutaric acid (OA, $1 \mathrm{mM}$ ) and ammonium persulfate (APS, $19 \mathrm{mM}$ ). Solution B was a mixture of acrylamide (AAm, $4 \mathrm{M})$, OA (1 mM), NaCl (80 mM), and APS (19 mM). At first, solution A was poured into a silicone mold, and preliminarily crosslinked by UV exposure ( $265 \mathrm{~nm}, 8$ $\mathrm{W}$ ) for $5 \mathrm{~h}$. The formed soft gel was then immersed in solution B for $14 \mathrm{~h}$ and further irradiated with UV for $5 \mathrm{~h}$ to to form a DN network. After washing with water for $24 \mathrm{~h}$, the DN gel sheet was immersed in $50 \mathrm{mM}$ McIlvaine buffer solution ( $\mathrm{pH} 5.0$ ) containing $200 \mathrm{mM}$ fructose solution for $24 \mathrm{~h}$.

\section{Preparation of Fructose $/ \mathrm{O}_{2}$ Fuel Cell}

The FDH-modified anode textile and the BOD-modified cathode textile were laminated to the opposite faces of the DN hydrogel sheet $(0.5 \mathrm{~mm}$ thick) made with 50 $\mathrm{mM}$ McIlvaine buffer solution ( $\mathrm{pH}$ 5.0) containing $200 \mathrm{mM}$ fructose. Although these electrodes were just stacked together with the hydrogel sheet without any adhesive materials, the assembled cell was mechanically stable enough for our measurements.

\section{Electrochemical Measurements}

The performance of the ST electrodes was analyzed by a three-electrode system (BSA, 730C electrochemical analyzer) in solution using an $\mathrm{Ag} / \mathrm{AgCl}$ reference and a platinum counter electrode. McIlvaine buffer ( $\mathrm{pH}$ 5.0) was used for evaluating the electrodes. $200 \mathrm{mM}$ fructose was added to the buffer for the FDH-modified anode. The performance of a biofuel cell sheet constructed with the fructose-containing DN hydrogel film ( $0.5 \mathrm{~mm}$ thick) was evaluated from the cell voltage upon connecting with a variable external resistance between $22 \Omega$ and $2.2 \mathrm{M} \Omega$. The current and the power were derived from the cell voltage and the resistance. Unless otherwise indicated, the electrochemical measurements were carried out at $25^{\circ} \mathrm{C}$.

\section{Results and Discussion}

\section{Electrical Conductivity of Textile Electrodes}

The electrical properties of the CNT-modified ST strips (0.18 mm thick) are shown in Table 1. Originally insulating, virgin ST drastically turned to be conductive by modification with high aspect ratio CNTs, compared to particulate ketjen black (KB). Particularly, the modification with SCNT achieved the conductivity of $\sim 200 \mathrm{mS} / \mathrm{cm}$. 
These results indicate that the length of CNTs determines conductivity of the modified ST. On the other hand, modification with MCNTs has been shown to be effective for constructing high-performance enzyme electrodes in our previous study (Miyake et al., 2013). Therefore, to achieve both high conductivity and enzymatic activity, we employed multi-modification of ST with both SCNT and MCNT (denoted as MCNT/SCNT/ST), and used it in the following studies. Scanning electron microscopy (SEM) observation indicated that ST fibers were uniformly coated by CNTs as well as interconnected by CNT bundles (Suppl. Fig. S1b).

Figure 2 shows (a) a photograph of the textile electrode under 50\% stretching, which is the largest strain possible at the junction part of the body (Yamada et al., 2011), and (b) electrical conductance during successive stretching at the elongation rate of $4 \mathrm{~mm} / \mathrm{s}$. The first 50\% stretching decreased the conductance to the one-third of the original value for both the MCNT/ST and the MCNT/SCNT/ST. Such large decrease in conductance did not occur in the case of $10 \%$ stretching. SEM observation indicated the partial breaking of the CNT bundles at the junction between the ST fibers (Supplementary Figure S3), probably due to slipping of the ST fibers during stretching. Importantly, this partial breaking of the conductive network occurs only on the first stretching, and the textile electrode showed stable conductive behavior in the subsequent cycles with reversible $30 \%$ fluctuation that corresponds to resistance changes of $30 \Omega$ for the case of the MCNT/SCNT/ST. Considering the use for the BFC that is generally operated with an external load of several $\mathrm{k} \Omega$ (Miyake et al., 2011b; Ogawa et al., 2015), it can be expected the comparatively small $30 \Omega$ fluctuation in electrode conductance would not significantly affect the total cell power.

[Table 1]

[Figure 2]

\section{FDH-Modified Textile Anode}

Figure 3a shows typical cyclic voltammograms of the FDH-modified MCNT/SCNT/ST electrode at $10 \mathrm{mV} / \mathrm{s}$ in a stirred buffer solution containing $200 \mathrm{mM}$ fructose, in which the maximum current density reached to $5 \mathrm{~mA} / \mathrm{cm}^{2}$ at $0.6 \mathrm{~V}$. The high performance obtained originated from the effective combination of the two types of CNTs, SCNT and MCNT. Use of either SCNT or MCNT alone was not sufficient; FDH-modified MCNT/ST electrode showed lower current density around $2 \mathrm{~mA} / \mathrm{cm}^{2}$ at $0.6 \mathrm{~V}$ probably due to the lower electrode conductivity. The current density obtained at the FDH-modified SCNT/ST electrode was also lower (around $1 \mathrm{~mA} / \mathrm{cm}^{2}$ ) probably due 
to the low activity of the surface of SCNT in the enzyme reaction.

Figure $3 \mathrm{~b}$ shows the changes in the current density at $0.6 \mathrm{~V}$ caused by repeated cycles of $10 \%$ and $50 \%$ stretching. The catalytic activity for fructose oxidation decreased during the initial few stretching cycles, but subsequently became stable and maintained the performance. This behavior is similar to the stability profile of electrode conductivity described above (Fig. 2). Even after 30 cycles of stretching, the FDH electrode maintained the current density around $5 \mathrm{~mA} / \mathrm{cm}^{2}$ for $10 \%$ stretching and 4 $\mathrm{mA} / \mathrm{cm}^{2}$ for $50 \%$ stretching.

[Fig.3]

\section{BOD-Modified $\mathrm{O}_{2}$-Diffusion Cathode}

Figure 4a shows cyclic voltammograms of a BOD-modified ST cathode at $10 \mathrm{mV} / \mathrm{s}$. The electrode strip was put on a pH 5.0 buffer solution to wet the BOD-modified face of the strip $\left(\mathrm{O}_{2}\right.$-diffusion configuration, solid line). Reduction current density reached -1.5 $\mathrm{mA} / \mathrm{cm}^{2}$ (at $0 \mathrm{~V}$ ), which is about 10 times larger than that measured by the same cathode strip immersed into an $\mathrm{O}_{2}$-saturated solution (immersed configuration, dashed line). This superior performance of the $\mathrm{O}_{2}$-diffusion configuration is due to effective $\mathrm{O}_{2}$ supply from the ambient air through the textile.

Figure $4 \mathrm{~b}$ shows the change in $\mathrm{O}_{2}$ reduction current at $0 \mathrm{~V}$, caused by successive $50 \%$ stretching cycles (solid line). The biocathode textile showed a similar profile as the anode (Fig. 3b), reflecting the partial breaking of the CNT network, but maintained -1 $\mathrm{mA} / \mathrm{cm}^{2}$ even after 30 stretching cycles. As explained in Materials and Methods section, the BOD-modified face was further coated by MCNT/PTFE mixture to ensure enough hydrophobicity even during stretching (Supplementary Figure S4). When PTFE was absent in the coating (dashed line in Fig. 4b), the lack of hydrophobicity allowed the penetration of water through the stretched textile, and caused significant decrease in the cathode performance due to the breakdown of the $\mathrm{O}_{2}$-diffusuion configuration.

[Fig.4]

\section{Laminated Fructose $/ \mathrm{O}_{2}$ Fuel Cell Sheet}

The FDH-modified anode textile and the BOD-modified cathode textile were laminated to the opposite faces of the DN hydrogel sheet. The hydrophilic anode was somewhat moistened by blotting of the fructose solution from the hydrogel sheet. On 
the other hand, the $\mathrm{O}_{2}$ reduction at the hydrophobic cathode proceeded at the three-phase boundary of the hydrogel-electrode interface. Figure 5a shows a typical example of the cell performance. The open-circuit voltage of the cell was $0.74 \mathrm{~V}$, which is similar to the difference between the potentials at which fructose oxidation and oxygen reduction begin in cyclic voltammograms $(-0.1 \mathrm{~V}$ in Fig. 3a and $0.58 \mathrm{~V}$ in Fig. 4a, respectively). The maximum current density and the power density were 1.0 $\mathrm{mA} / \mathrm{cm}^{2}$ and $0.25 \mathrm{~mW} / \mathrm{cm}^{2}$, respectively, which were determined by the BOD-cathode because of its comparatively inferior performance compared to the FDH anode. Figure $5 \mathrm{~b}$ shows that the current and power densities (with an external load of $1.2 \mathrm{k} \Omega$ ) decreased to $0.6 \mathrm{~mA} / \mathrm{cm}^{2}$ and $0.2 \mathrm{~mW} / \mathrm{cm}^{2}$, respectively, and was stable during the $50 \%$ stretching cycles. The stretchability of the textile-based BFC originates from the flexible meshwork structure of the textile; the base fibers (nylon/polyurethane co-fiber) themselves are not significantly expanded during the stretching of the textile. Therefore the CNTs and enzymes are stable on the fibers except for the part of junctions, and can maintain their performance even under continuous stretching.

As shown in the photos in Fig. 5c, the deviations of cell power during deformations were evaluated by using a LED device consisting of a charge pump IC, a $1 \mathrm{mF}$ ceramic capacitor, and a red LED. The power generated by BFCs were once stored by the capacitor, and discharged to the LED when the voltage of capacitor reaches $2 \mathrm{~V}$. Therefore, the frequency of the resulting periodic LED blink (Fig. 5d) is positively correlating with the cell power (Hanashi et al., 2009; Yoshino et al., 2013). As shown in Fig. 5e, the blinking frequency (namely, cell power) derived from Fig. 5d was almost constant during the stretching because of the robustness of the MCNT/PTFE-coated $\mathrm{O}_{2}$-diffusion cathode even in the stretched form (Suppl. Fig. S4). Such robustness of the ST-based biofuel cell was also examined for the $180^{\circ}$ twisting and wrapping on a glass tube (0.7 cm diameter) (see Supplementary Movie 1). The blinking frequency in each form was almost the same as the original state, which indicates that the developed cell was stretchable and flexible enough to operate in various forms.

[Fig.5]

\section{Conclusion}

We have developed a stretchable textile (ST)-based biofuel cell by laminating an FDH-modified anode textile, fructose-containing DN hydrogel film, and BOD-modified cathode textile for reduction of ambient $\mathrm{O}_{2}$. The pre-modification with CNTs made an ST strip conductive enough for enzyme electrodes. The performance of the anode, the 
cathode, and the laminated cell degraded to some degree by the few initial stretching cycles, but afterward became constant even during the stretching, twisting, and wrapping. The stretchable biofuel cell may be integrated into wearable devices in the future, and the development of techniques for practical use, such as packaging with $\mathrm{O}_{2}$ permeable films, is in progress.

\section{Acknowledgement}

The authors thank Dr. Takeo Yamada and Dr. Kenji Hata, National Institute of Advanced Industrial Science and Technology (AIST), for their kind cooperation in the preparation of SCNT. This work was partly supported by Regional Innovation Strategy Support Program “Knowledge-based Medical Device Cluster/Miyagi Area”, Creation of Innovation Center for Advanced Interdisciplinary Research Area, Center of Innovation S\&T Based Radical Innovation and Entrepreneurship Program (COI-STREAM), and by Grand-in-Aid for Scientific Research A (25246016) and Challenging Exploratory Research (K15K13315) from the Ministry of Education, Culture, Sports, Science and Technology, Japan.

\section{References}

Ata, S., Kobashi, K., Yumura, M., Hata, K., 2012. Nano Lett. 12, 2710-2716.

Bandodkar, A.J., Wang, J., 2014. Trends Biotechnol. 32, 363-371.

Barton, S.C., Gallaway, J., Atanassov, P., 2004. Chem. Rev. 104, 4867-4886.

Cooney, M.J., Svoboda, V., Lau, C., Martin, G., Minteer, S.D., 2008. Energy Environ. Sci. 1, 320-337.

Cosnier, S., Le Goff, A., Holzinger, M., 2014. Electrochem. Commun. 38, 19-23.

Gong, J.P., Katsuyama, Y., Kurokawa, T., Osada, Y., 2003. Adv. Mater. 15, 1155-1158.

Gong, J.P., 2010. Soft Matter 6, 2583-2590.

Hammock, M.L., Chortos, A., Tee, B.C.K., Tok, J.B.H., Bao, Z., 2013. Adv. Mater. 25, 5997-6038.

Hanashi, T., Yamazaki, T., Tsugawa, W., Ferri, S., Nakayama, D., Tomiyama, M., Ikebukuro, K., Sode, K., 2009. Biosens. Bioelectron. 24, 1837-1842.

Hattori, Y., Falgout, L., Lee, W., Jung, S.Y., Poon, E., Lee, J.W., Na, I., Geisler, A., Sadhwani, D., Zhang, Y., Su, Y., Wang, X., Liu, Z., Xia, J., Cheng, H., Webb, R.C., Bonifas, A.P., Won, P., Jeong, J.W., Jang, K.I., Song, Y.M., Nardone, B., Nodzenski, M., Fan, J.A., Huang, Y., West, D.P., Paller, A.S., Alam, M., Yeo, W.H., Rogers, J.A., 2014. Adv. Healthc. Mater. 3, 1597-1607. Hayashi, T., Yamazaki, T., Tsugawa, W., Ferri, S., Nakayama, D., Tomiyama, M., Ikebukuro, K., 
Sode, K., 2009. Biosens. Bioelectron. 24, 1837-1842.

Heller, A., 2004. Phys. Chem. Chem. Phys. 6, 209-216.

Hu, L., Pasta, M., Mantia, F.L., Cui, L., Jeong, S., Deshazer, H.D., Choi, J.W., Han, S.M., Cui, Y., 2010. Nano Lett. 10, 708-714.

Jia, W., Valdes-Ramirez, G., Bandodkar, A.J., Windmiller, J.R., Wang, J., 2013a. Angew. Chem. 52, 7233-7236.

Jia, W., Bandodkar, A.J., Valdes-Ramirez, G., Windmiller, J.R., Yang, Z., Ramirez, J., Chan, G., Wang, J., 2013b. Anal. Chem. 85, 6553-6560.

Jia, W., Wang, X., Imani, S., Bandodkar, A.J., Ramírez, J., Mercier, P.P., Wang, J., 2014. J. Mater. Chem. A 2, 18184-18189.

Kwon, C.H., Lee, S.H., Choi, Y.B., Lee, J.A., Kim, S.H., Kim, H.H., Spinks, G.M., Wallace, G.G., Lima, M.D., Kozlov, M.E., Baughman, R.H., Kim, S.J., 2014. Nat. Commun. 5, 3928.

Lipomi, D.J., Tee, B.C., Vosgueritchian, M., Bao, Z., 2011. Adv. Mater. 23, 1771-1775.

Luckarift, H.R., Atanassov, P.B., Johnson, G.R., 2014. Enzymatic fuel cells: From fundamentals to applications. First ed. John Wiley \& Sons.

Mano, N., Edembe, L., 2013. Biosens. Bioelectron. 50, 478-485.

Meredith, M.T., Minteer, S.D., 2012. Annu. Rev. Anal. Chem. 5, 157-179.

Miyake, T., Haneda, K., Nagai, N., Yatagawa, Y., Onami, H., Yoshino, S., Abe, T., Nishizawa, M., 2011a. Energy Environ. Sci. 4, 5008-5012.

Miyake, T., Haneda, K., Yoshino, S., Nishizawa, M., 2013. Biosens. Bioelectron. 40, 45-49.

Miyake, T., Yoshino, S., Yamada, T., Hata, K., Nishizawa, M., 2011b. J. Am. Chem. Soc. 133, 5129-5134.

Murata, K., Kajiya, K., Nakamura, N., Ohno, H., 2009. Energy Environ. Sci. 2, 1280-1285.

Ogawa, Y., Kato, K., Miyake, T., Nagamine, K., Ofuji, T., Yoshino, S., Nishizawa, M., 2015. Adv. Healthc. Mater. 4, 506-510.

Park, S.I., Xiong, Y., Kim, R.H., Elvikis, P., Meitl, M., Kim, D.H., Wu, J., Yoon, J., Yu, C.J., Liu, Z., Huang, Y., Hwang, K.C., Ferreira, P., Li, X., Choquette, K., Rogers, J.A., 2009. Science 325, 977-981.

Qi, Y., Kim, J., Nguyen, T.D., Lisko, B., Purohit, P.K., McAlpine, M.C., 2011. Nano Lett. 11, 1331-1336.

Sekitani, T., Nakajima, H., Maeda, H., Fukushima, T., Aida, T., Hata, K., Someya, T., 2009. Nat. Mater. 8, 494-499.

Shleev, S., Tkac, J., Christenson, A., Ruzgas, T., Yaropolov, A.I., Whittaker, J.W., Gorton, L., 2005. Biosens. Bioelectron. 20, 2517-2554.

So, K., Kawai, S., Hamano, Y., Kitazumi, Y., Shirai, O., Hibi, M., Ogawa, J., Kano, K., 2014. Phys. Chem. Chem. Phys. 16, 4823-4829. 
Someya, T., 2012. Stretchable electronics. First ed. John Wiley \& Sons.

Tominaga, M., Nomura, S., Taniguchi, I., 2009. Biosens. Bioelectron. 24, 1184-1188.

Tominaga, M., Shirakihara, C., Taniguchi, I., 2007. J. Electroanal. Chem. 610, 1-8.

Tsujimura, S., Nishina, A., Hamano, Y., Kano, K., Shiraishi, S., 2010. Electrochem. Commun. 12, 446-449.

Wu, Z.L., Gong, J.P., 2011. NPG Asia Mater. 3, 57-64.

Yamada, T., Hayamizu, Y., Yamamoto, Y., Yomogida, Y., Izadi-Najafabadi, A., Futaba, D.N., Hata, K., 2011. Nat. Nanotech. 6, 296-301.

Yoshino, S., Miyake, T., Yamada, T., Hata, K., Nishizawa, M., 2013. Adv. Energy Mater. 3, 60-64. 


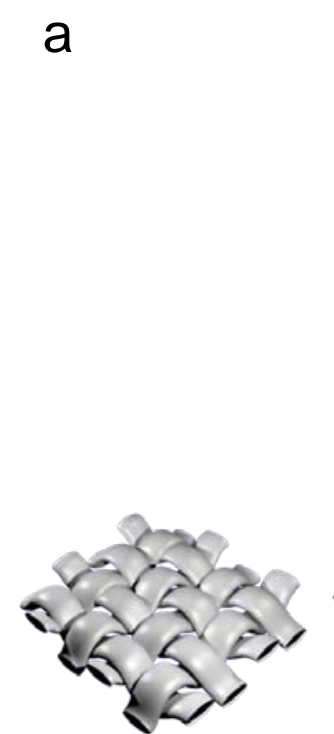

Stretchable Textile

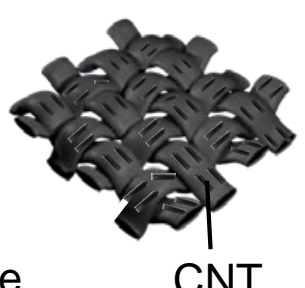

CNT

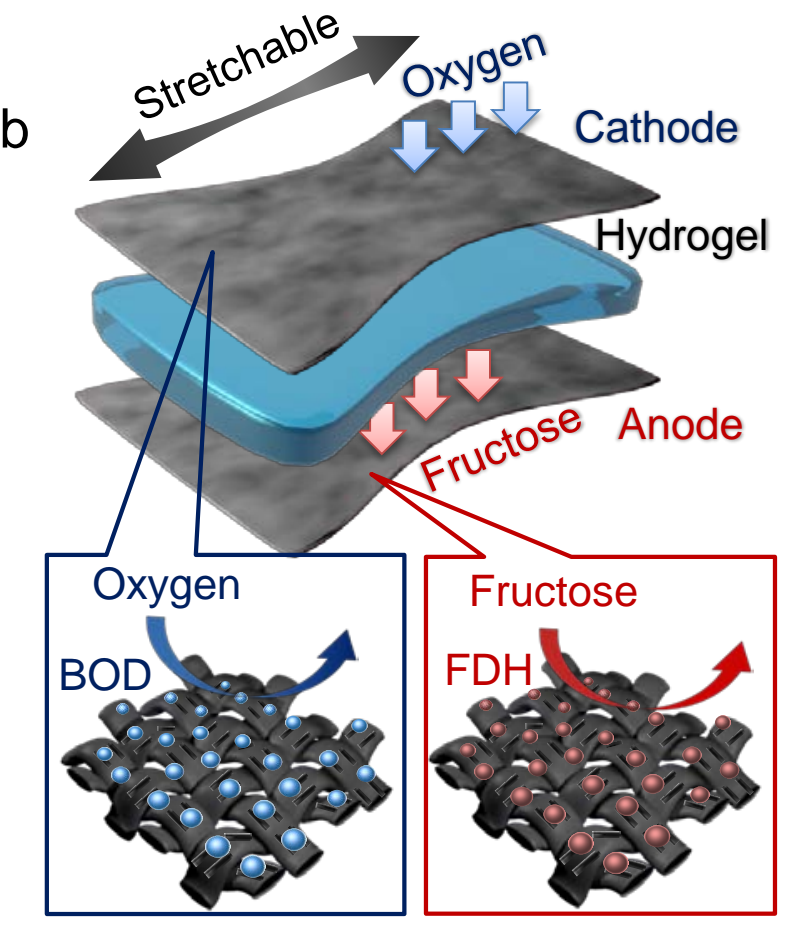

Figure 1. (a) Photographs and illustrations of virgin and CNT-modified ST strips. The scale bar indicates $5 \mathrm{~mm}$. (b) A schematic of a stretchable biofuel cell constructed by laminating enzyme-modified conductive textiles with a hydrogel film that retains electrolyte solution and fructose fuel.

Table 1. Conductive properties of ST strips modified with nanocarbons.

\begin{tabular}{cccccc}
\hline & PT & KB/ST & MCNT/ST & SCNT/ST & MCNT/SCNT/ST \\
\hline $\begin{array}{c}\text { Conductance } \\
\text { (mS) }\end{array}$ & 0 & $0.5 \pm 0.07$ & $7 \pm 0.3$ & $35 \pm 2.0$ & $35 \pm 0.9$ \\
$\begin{array}{c}\text { Conductivity } * \\
\text { (mS/cm) }\end{array}$ & 0 & $2.7 \pm 0.4$ & $38 \pm 1.6$ & $194 \pm 11$ & $194 \pm 5$ \\
\hline
\end{tabular}

The number of samples $\mathrm{N}=4$

*calculated by assuming material thickness as $0.18 \mathrm{~mm}$ 

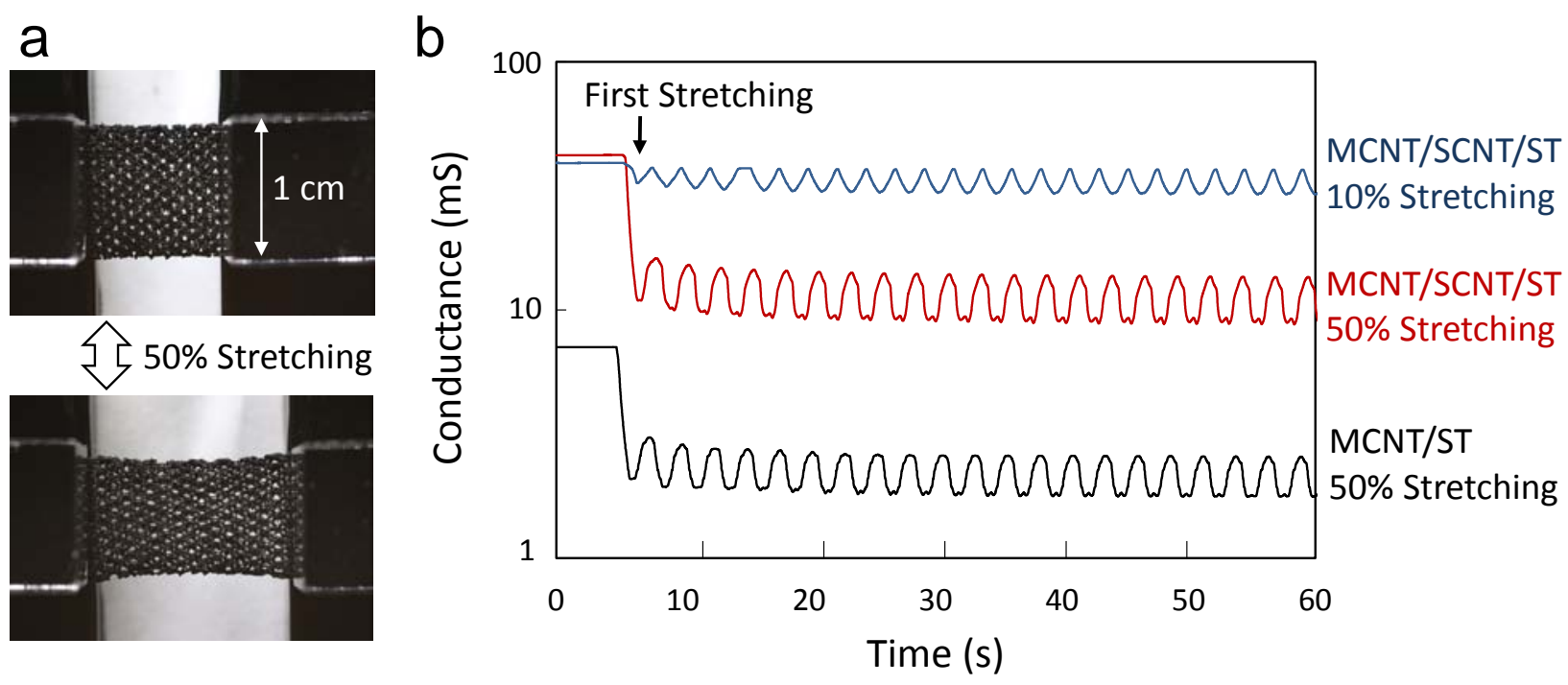

Figure 2. (a) Photographs showing 50\% stretching of a CNT-modified ST strip. (b) Electrical conductance of the MCNT/SCNT/ST strips monitored by applying $0.3 \mathrm{~V}$ during successive $10 \%$ (blue line) or 50\% (red line) stretching. The black line depicts the result of $50 \%$ stretching of the ST strip modified only with MCNT.

a

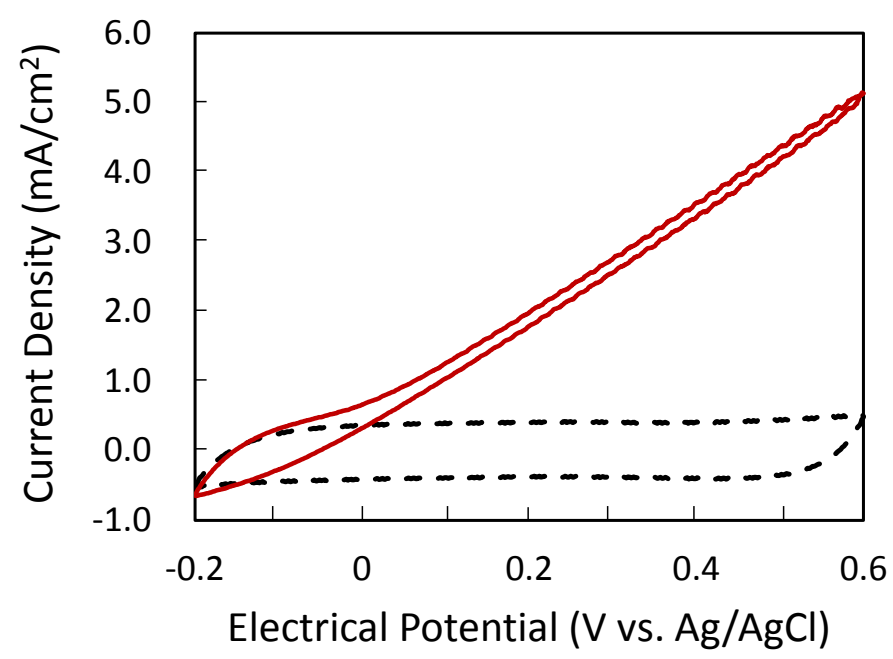

b

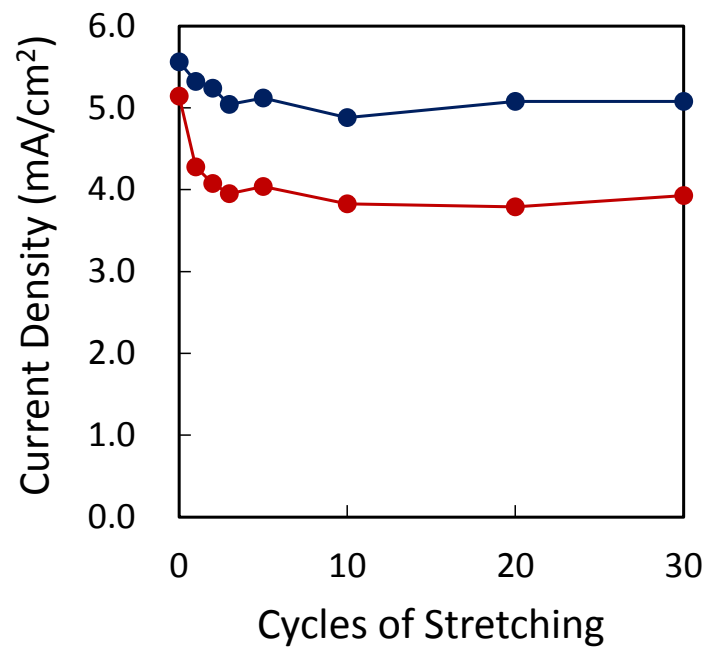

Figure 3. (a) A cyclic voltammogram of the FDH-modified MCNT/SCNT/ST electrode at $10 \mathrm{mV} / \mathrm{s}$ in a stirred $200 \mathrm{mM}$ fructose solution. A voltammogram without fructose as a negative control is also shown by a dashed black line. (b) Deviation in the current density at $0.6 \mathrm{~V}$ on successive stretching in the strain range of $10 \%$ (blue) and $50 \%$ (red). 

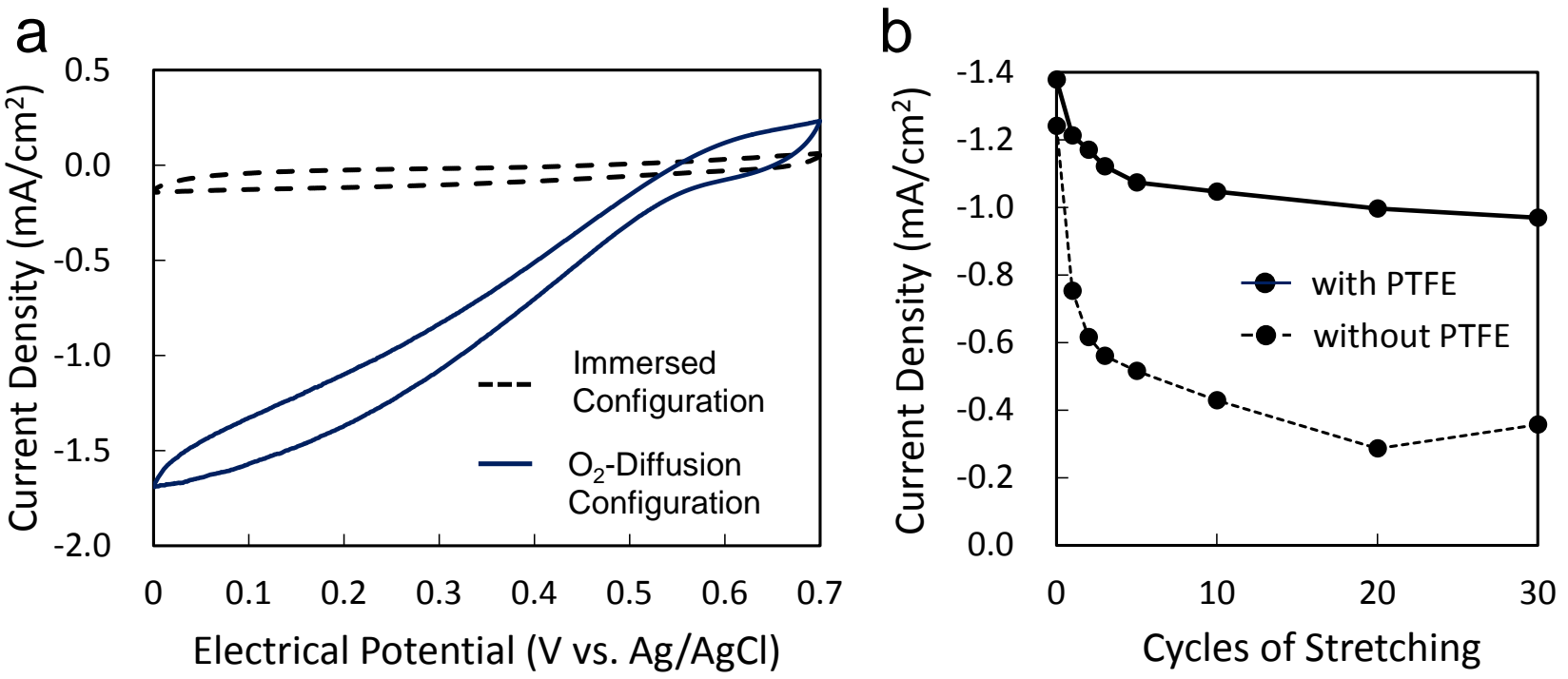

Figure 4. (a) Cyclic voltammograms $(10 \mathrm{mV} / \mathrm{s})$ of a BOD-modified ST-based cathode strip immersed in a pH 5.0 buffer solution (immersed configuration, dashed line) or put on the solution $\left(\mathrm{O}_{2}\right.$-diffusion configuration, solid line). (b) Deviation in the current density at $0 \mathrm{~V}$ on successive $50 \%$ stretching of the cathode strips. The strips with (solid line) and without (dashed line) further coating with MCNT/PTFE mixture were studied. 
a

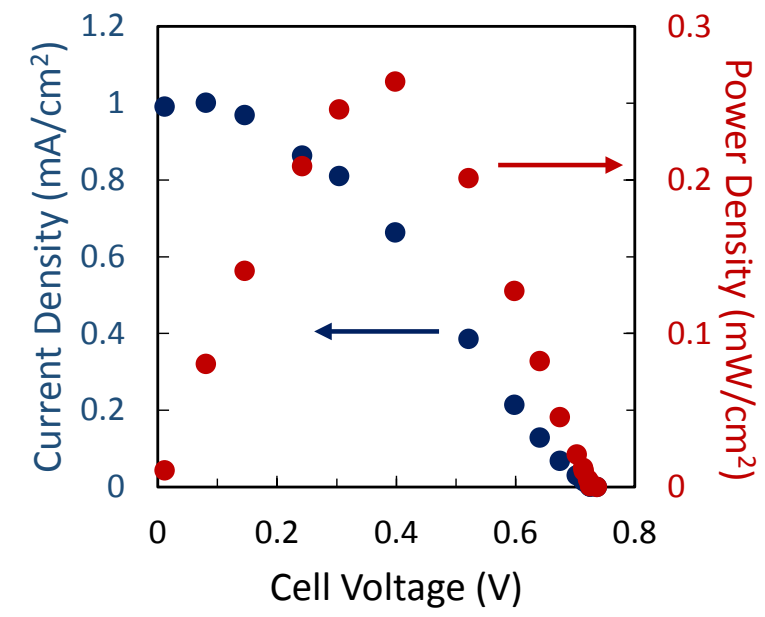

C Stretched Form

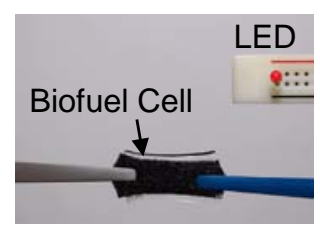

b

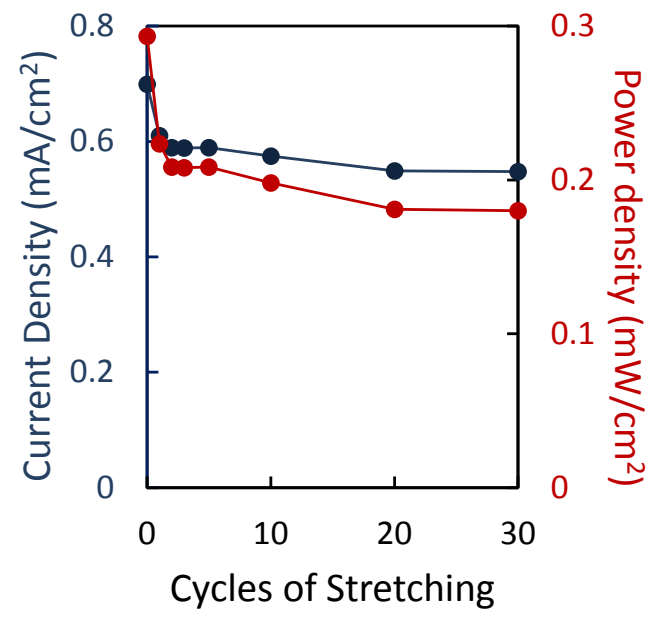

Wrapped Form

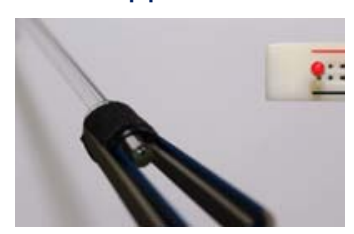

d

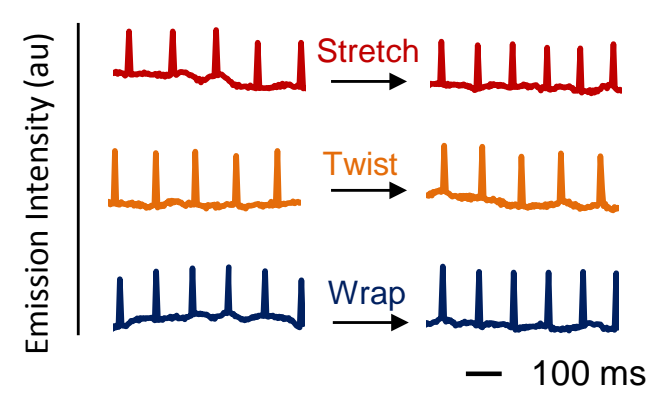

e

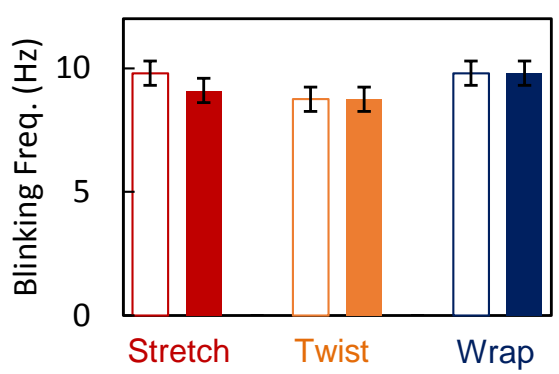

Figure 5. (a) Performance of an as-constructed biofuel cell with the internal hydrogel film (0.5 mm thickness) containing $50 \mathrm{mM}$ Mcllvaine buffer ( $\mathrm{pH}$ 5.0) and $200 \mathrm{mM}$ fructose. The current and the power were derived from the cell voltage and the external resistance (22 $\Omega \sim 2.2 \mathrm{M} \Omega$ ). (b) Deviation in the current and power densities (with 1.2 $\mathrm{k} \Omega$ load) on successive $50 \%$ stretching. (c) Photographs of the biofuel cell in stretched, twisted, and wrapped forms taken from the Supplementary Movie 1. (d) The time course of the LED device before (left) and during (right) different kinds of deformations (red: stretching, orange: twisting, blue: wrapping). (e) Averaged blinking frequencies of the LED device before (unfilled) and during (filled) the deformations. 